\title{
6 Building of the Managerial Synapse
}

\section{Main Variables Influencing the Managerial Synapse}

Managerial synapse construction, work, functioning, and performance are influenced by many variables (see Figure 6.1), which can be divided into two categories:

a Direct variables, whose parameters have a straightforward and major influence on the elements associated with the managerial synapse. They can be separated, taking into consideration their appurtenance, into two groups:

- Organizational variables, referring to the company involved and if another relevant stakeholder of the managerial synapse is from an outside entity - to its organization. Hence, in a managerial synapse, it is mandatory to be involved in at least the variables concerning one organization - the company involved;

- Individual variables, reflecting the characteristics of the people who are acting as relevant stakeholders in the managerial synapse from the company or from the other organization. In a managerial synapse, we always have two sets of individual variables, one for each component.

b Indirect variables, which reflect the elements of the environment in which the company and - if such is the case - the other organization with a component in the managerial synapse are integrated. Indirect variables influence the building, work and performance of the managerial synapse mainly through providing - or not - enabling contextual conditions. Usually, the impact of indirect variables on the managerial synapse is smaller than the influence of the direct variables. In certain circumstances - like the crisis generated by the COVID-19 pandemic the impact of this category of variables could be substantial.

In Figure 6.1, we include the direct and indirect variables that, in our opinion, usually influence, and with substantial intensity, a managerial

DOI: $10.4324 / 9781003217701-6$ 


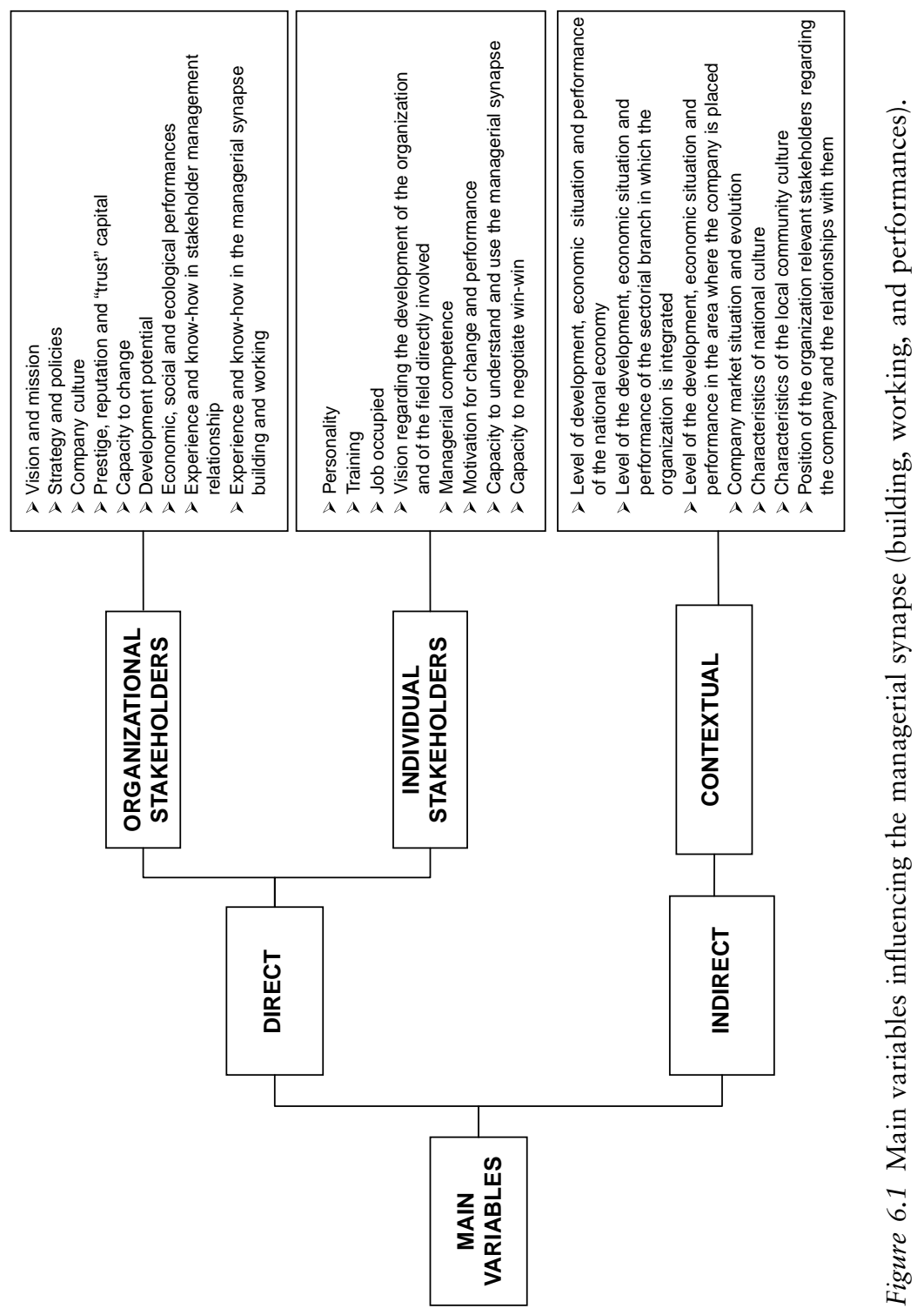


synapse. Of course, in special situations, some of these variables could be less relevant and/or other variables, not included in our framework, could have a major influence on the managerial synapse.

The framework with the main variables impacting the managerial synapse could be very helpful, especially at the beginning of building and using the managerial synapses in the company. Also, these variables can contribute to the higher valorization of the huge potential for development and performance increasing of managerial synapse.

The management of the company, together with the individual managers, components of the managerial synapses, should evaluate carefully these variables, in order to valorize their positive characteristics and impact and to avoid and/or reduce the negative aspects regarding the variables. It is recommended that the indirect variables and the organizational variables should be evaluated at the level of the company, and the results used in all managerial synapses. Evaluation of the individual variables should be done at the level of each managerial synapse.

\section{Approaches and Premises in the Managerial Synapse Construction}

The managerial synapse, which represents a specific managerial mechanism, in order to be performant, should be constructed using a specific approach that is able to take into consideration its specific particularities, and the company and its relevant stakeholders' strategies and policies.

There are two ways of approaching the building of a managerial synapse:

a The construction of the managerial synapse by itself, considering that it is an autonomous entity, connected to other components of the company utilizing the usual type of managerial processes and relationships;

$\mathrm{b}$ The construction of the managerial synapse treated as a basic component of the stakeholder management-based system of the company, which is developed, concomitantly, within a comprehensive holistic designing of the entire organization.

We will use the first approach because the building of a managerial synapse as such, as distinct from the other managerial settings, contains the essential elements involved in the case of the second option for its building.

Construction of the managerial synapse is based on three premises (see Figure 6.2).

Building a managerial synapse means more than constructing a managerial mechanism. It means developing a specific multidimensional 


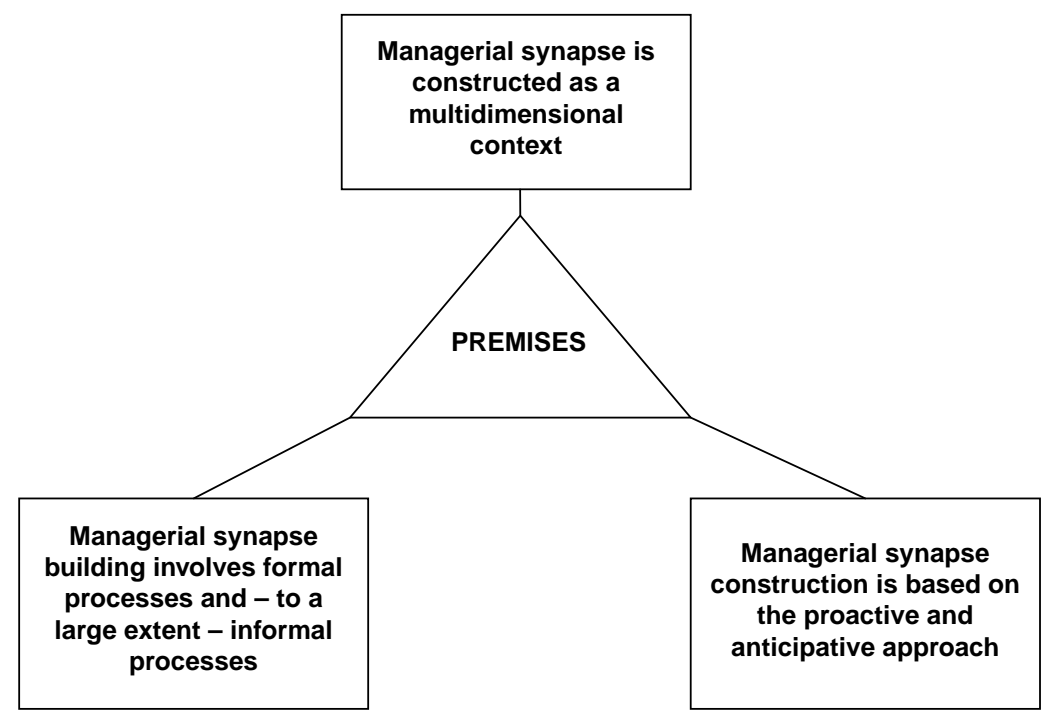

Figure 6.2 Premises for building performant managerial synapse.

context focused on the synapse managerial area. This context is a precondition in order to generate consistent synergy for both components of the synapse and for the company. In fact, increasing the contextual approach in organizations represents a general trend (Johns, 2017), both in social science and in business and managerial praxis.

The design of the managerial synapse should be based on anticipative and proactive thinking and analysis. Characteristics of the managerial synapse should be designed and implemented so as to be able to satisfy the challenges and the requirements of the company and relevant stakeholders in the next period. Such an approach makes the managerial synapse not only performant in the next period but also sustainable in the long run.

Construction of the managerial synapse involves both formal and informal processes. The essential managerial elements of the synapse common objectives, main tasks, competences and responsibilities, major methods and techniques to be used, resources allocated, and performance evaluation criteria - should be defined from the beginning by the list of objectives and goals, job description, budgets, list of methods and techniques, etc. The formalized design should determine only the essential elements for each managerial synapse. In order to enhance the innovative approach, flexibility, and entrepreneurial spirit, it is necessary for the many details involved in the managerial synapse to be determined informally, by both components, valorizing their creativity, initiative and desire to be very competitive. 


\section{Building of the Managerial Synapse}

An essential element in the managerial synapse construction is the establishment of joint stakeholders' objectives and/or goals, starting from the company's core mission. There are mainly three models that could be used:

- SMART model of setting objectives, classical, developed and used in management by objectives (MBO system) (Drucker, 1954; Odiorne, 1965). According to this model, the objectives to be achieved in a company, part of a company, or at the level of an individual component should be specific, measurable, agreed, realistic, and time bounded. The SMART model has been used with very good results, especially in industrial companies, where the production activities have been predominant. The management by objectives system and SMART objectives approach started to be less frequently used at the end of the last century, when creative, innovational and qualitative processes became decisive for performance, and when the information revolution, and later the knowledge revolution, occurred.

- Process-centred objectives model, which emerged in the last quarter of the twentieth century in order to overcome the limits of the SMART model. The approach is based on the establishment of a hierarchy of goals, for entire companies, teams, and individuals. The processes are focused on describing each task that an individual manager or executant has to carry out and on establishing operating standards for which individual objectives are determined. This model has been used successfully in the well-known Total Quality Management and Continue Improvement Management Systems (Creech, 1994; Juran, 1995), favouring to a large extent the discovery of weaknesses and errors, and transforming them into opportunities for improvement and development, in spite of the notable bureaucracy involved.

- Contingency model of objectives, proposed recently by Manning (2017), which tries to cumulate the advantages of the previous two models and reduce their limits. Essentially, this model divides the tasks to be fulfilled into two categories:

- clear and straightforward tasks, for which the SMART objectives model is used;

- complex, ambiguous and changeable tasks, for which an approach based mainly on the process-centred objectives model is used.

There are three stages of the contingent objectives setting: work out the level of straightforwardness or of complexity of the tasks at hand; work out the best type of objectives for the task at hand and level of complexity expected to be encountered; and agree between the manager and 
stakeholders a set of contingent objectives and goals and how to measure and describe their achievement.

The competitive advantages of this model are:

- the possibility of taking into account the level of complexity, ambiguity, and change inherent to a task, which favours innovative, flexible, and entrepreneurial individual and team actions and behaviours; this type of process is more frequent in the last period of the transition to the knowledge-based economy and digital economy;

- the possibility of getting the maximum results from the straightforward tasks, using mainly the SMART objectives model;

- the possibility of allowing managers and executants to change the nature of the objectives-setting processes, in order to fit to the tasks they should achieve, which, in the present VUCA environment, change quite often.

In the establishment of the objectives of each managerial synapse, one of the three models presented should be chosen. The most suitable model is quite probably the contingency model of objectives. Of course, major attention should be paid to the specificity of the relevant stakeholder involved in the synapse, especially when he(she) is from outside the company.

In Table 6.1, we present an indicative guide regarding the type of objective model setting in the most frequent types of managerial synapse.

Concomitantly with the determination of the joint objectives, it is necessary for both components of the managerial synapse to collaborate, in order to determine the criteria of the evaluation of the objectives fulfilment. Knowing the evaluation criteria from the beginning of the managerial synapse building will increase the stakeholders' motivation to achieve the joint goals and objectives, and the chance of long-run performances and sustainability.

In the setting of the joint goals and objectives using win-win negotiation, the type of relation between the relevant stakeholders should be taken into consideration (Brown, Gianiodis, \& Santoro, 2017) in forming the managerial synapse. There are mainly two types of relationships within a managerial synapse:

- cooperative relationships;

- co-opetition relationships, which means concomitantly relationships of cooperation, but also relationships of competition between both managerial synapse components.

In the case of exclusive cooperative relationships between components of a managerial synapse, the establishment of joint goals, objectives, and expectations is easier and faster. 


\section{Building of the Managerial Synapse}

Table 6.1 The use of the model's objectives settings for the different types of managerial synapse

\begin{tabular}{|c|c|c|c|c|c|}
\hline No. & $\begin{array}{l}\text { Managerial } \\
\text { Synapse Type }\end{array}$ & $\begin{array}{l}\text { SMART } \\
\text { Objectives } \\
\text { Model }\end{array}$ & $\begin{array}{l}\text { Process- } \\
\text { Centred } \\
\text { Objectives } \\
\text { Model }\end{array}$ & $\begin{array}{l}\text { Convergence } \\
\text { Objectives } \\
\text { Model }\end{array}$ & Observations \\
\hline 1. & $\begin{array}{l}\text { Company } \\
\text { manager - } \\
\text { employee }\end{array}$ & $\mathrm{x}$ & $\mathrm{x}$ & $\mathrm{x}$ & $\begin{array}{l}\text { Depends on } \\
\text { the type of } \\
\text { tasks } \\
\text { involved }\end{array}$ \\
\hline 2. & $\begin{array}{l}\text { Company } \\
\text { manager - } \\
\text { client }\end{array}$ & $\mathrm{x}$ & & $\mathrm{x}$ & \\
\hline 3. & $\begin{array}{l}\text { Company } \\
\text { manager - } \\
\text { supplier }\end{array}$ & $\mathrm{x}$ & & & \\
\hline 4. & $\begin{array}{l}\text { Company top } \\
\text { management } \\
\text { body - } \\
\text { company } \\
\text { manager }\end{array}$ & $\mathrm{x}$ & $\mathrm{x}$ & $\mathrm{x}$ & $\begin{array}{l}\text { Depends on } \\
\text { the type of } \\
\text { activities of } \\
\text { the manager }\end{array}$ \\
\hline 5. & $\begin{array}{l}\text { Company top } \\
\text { management } \\
\text { body - } \\
\text { company } \\
\text { shareholder }\end{array}$ & $\mathrm{x}$ & & $\mathrm{x}$ & \\
\hline 6. & $\begin{array}{l}\text { Company top } \\
\text { management } \\
\text { body - } \\
\text { company } \\
\text { outside investor }\end{array}$ & $\mathrm{x}$ & & & $\begin{array}{l}\text { Depends on } \\
\text { the type of } \\
\text { investment }\end{array}$ \\
\hline 7. & $\begin{array}{l}\text { Company } \\
\text { manager - } \\
\text { banker }\end{array}$ & $\mathrm{x}$ & & & $\begin{array}{l}\text { Depends on } \\
\text { the type of } \\
\text { activities }\end{array}$ \\
\hline 8. & $\begin{array}{l}\text { Company } \\
\text { manager - } \\
\text { consultant }\end{array}$ & & $\mathrm{x}$ & $\mathrm{x}$ & \\
\hline 9. & $\begin{array}{l}\text { Company } \\
\text { manager - } \\
\text { trainer }\end{array}$ & & $\mathrm{x}$ & & \\
\hline 10. & $\begin{array}{l}\text { Company } \\
\text { manager - } \\
\text { researcher }\end{array}$ & & $\mathrm{x}$ & & \\
\hline 11. & $\begin{array}{l}\text { Company } \\
\text { manager - } \\
\text { designer }\end{array}$ & & $\mathrm{x}$ & $\mathrm{x}$ & $\begin{array}{l}\text { Depends on } \\
\text { the type of } \\
\text { activities }\end{array}$ \\
\hline 12. & $\begin{array}{l}\text { Company } \\
\text { manager - local } \\
\text { community }\end{array}$ & & $\mathrm{x}$ & $\mathrm{x}$ & $\begin{array}{l}\text { Depends on } \\
\text { the type of } \\
\text { goals and/or } \\
\text { activities } \\
\text { involved }\end{array}$ \\
\hline
\end{tabular}


In the case of co-opetition relationships, the negotiation is more complicated and difficult because, as well as the common goals, objectives, and expectations, there are divergent or even opposite goals, objectives, and expectations. In such a situation, the successful finalization of the negotiation depends on the importance for each synapse component of the cooperative goals, objectives, and expectations compared with the different or opposite goals, objectives, and expectations. If the first category is more important for both parts - and usually it should be - the capacity to make a compromise for each part is essentially in order to determine joint, feasible, and performant goals and objectives for the managerial synapse.

The approaches presented by us in this section generate the best results when the company is truly a purpose-driven organization, which is based on the management logic of purpose. Fulfilment of personal purposes within organizational purposes is the essence of truly purpose-driven organizations (Rey, Velasco, \& Almandoz, 2019). A managerial synapse represents a mechanism that is able to implement this innovative vision.

\section{Stakeholders' Win-Win Negotiation Based on Multifaceted Motivation}

In the achievement of a managerial synapse, a crucial role is played by the negotiation between the two parties - the company manager and the inside or outside organization relevant stakeholder. Negotiation is a form of social exchange where the negotiators seek to reach an agreement with the other party. It involves, concomitantly, processes of competing and cooperating between the persons involved. Negotiation is dual-purpose, because it consists of both bargaining and problem solving (Bridoux, Coeurderoy, \& Durand, 2017).

In our opinion, the negotiation between stakeholders, in order to construct and implement a performant managerial synapse, should be based on the following premises regarding the individual motivation:

a Motivations of the people involved in the negotiation are of multiple natures. According to the heterogeneity theory of motivation (Hahn, 2015; Ingerson, DeTienne, \& Liljenquist, 2015; Olekalns \& Druckman, 2014), "human motivation" does not only individualistically conform to the instrumentalism philosophy (Cheng, Huang, $\& \mathrm{Su}, 2017)$ and practice - which is still predominant today. Very few people are $100 \%$ individualistic, focusing only on their selfinterests, without paying attention to the needs and interest of family members, friends, organizations, fellows, local community, etc. Concomitantly, very few people are $100 \%$ altruistic, not caring at all about their own needs and interests and only focusing on the interests of other people, organizations, communities, etc. Without 
any doubt, the majority of people - if not all - have mixed motivations, both individualistic and altruistic of course, varying from one person to other, and from one period to another.

b Motivations are different to a large extent from one person to another, because of many variables, which can be grouped into three main categories:

- Individual - character, education, past experience, health, human models taken into consideration, personal standard of living, etc.

- Organizational - company strategies and policies, organizational culture, company manager type (participative, authoritarian, mix), managerial leadership, motivational methods and techniques used, human resources management utilized, etc. Organizational variables refer to the company in which the relevant stakeholder is working and to the partner organization, in the case that the second component of the managerial synapse represents another organization (supplier, investor, client, etc.).

- Social - community, territorial and national culture, characteristics of the education and training system, ecological movements, social degree of bureaucracy and corruption, country economic-social development, etc.

All these variables - and not only them - influence the intensity and the structure of the individualistic and altruistic motivations of every person.

c There are many approaches to be utilized in order to encourage one person to change to a certain degree the motivations and the relationships from individualistic to altruistic ones. These approaches refer especially to the individual and organizational variables mentioned before, in the short term, and to the social variables in the medium and long term. Among these approaches, we mention: positive communication, training, mentoring, coaching, remodelling of the organization culture, change of the company motivation methods and techniques, new types of organization strategies, and policies focused on the relevant stakeholder's valorization and others.

$\mathrm{d}$ Change at the level of each person of the intensity and types of motivations, including the relation between individualistic and altruistic motivations, is reflected in the modification of his/her personal behaviours and actions, inside and outside the company. For example, the increase of stakeholders' altruistic motivations will determine more orientation toward the achievement of organizational and social goals using cooperative behaviour and actions, and sharing more intensive their own knowledge and other assets, etc.

e The negotiation approach in the company should be differentiated according to: 
- Stakeholder category (customers, suppliers, employees, etc.), bearing in mind that each of them has specific types of interests and dominant characteristics of work processes, which make certain specific elements in the negotiation necessary.

- Each relevant stakeholder category has certain strengths and vulnerabilities to consider, in order to get positive results.

- Each individual stakeholder, from every stakeholder category, presents many particular features, interests, approaches, expectations and motivations. Knowing and taking them into consideration is very helpful in order to achieve win-win negotiations.

These five premises indicate that the negotiation between the two relevant stakeholders involved in the managerial synapse might be and should be win-win. Also, they provide many useful elements for the achievement of the win-win negotiation faster, more easily and in a more performant manner. In order to do so, the negotiation with stakeholders should be reconceptualized. There are several ways recommended by specialists to achieve this. We will briefly present two of them, which are similar in some respects.

The first is reconceptualization of negotiation focusing more on mediation (Mehta \& Ripol, 2017). Managers and other stakeholders need to replace the classical negotiation, where the win is achieved usually in the form of forcing the other party to accept something of lesser value, with negotiation based on mediation. In this type of negotiation, the company manager and the other relevant stakeholder involved have to see beyond positions and numbers to get what really matters the most. Each participant should have and use a mediator mindset, which facilitates mutual understanding and harmonization of objectives, decisions and actions. For the development of successful negotiation - win-win negotiation based on mediation - it is essential to know the main obstacles, and the techniques to be used in order to overcome them. In Table 6.2, we present a sample of these elements, very well identified by Mehta and Ripol (2017).

Ingerson, DeTienne, and Liljenquist (2015) documented very well another way to reconceptualize negotiation - a relational approach to negotiation. They formulated this new approach after profound analysis of instrumentalism, revealing, besides its merits, many serious limitations: extremely selfish approach, cynical interpretation of people's behaviour, disproportionate focus on easily quantified outcomes, usually economic ones, marginalization of the relational and other non-quantified outcomes, pursuit of economic gains at the expense of relational gains, etc.

Relational negotiations are characterized by strong rationality. This means, according to Slife and Wiggins (2009), "the most reality of the 


\section{Building of the Managerial Synapse}

Table 6.2 Major obstacles in company management negotiation, ways and techniques to overcome them

\begin{tabular}{|c|c|c|c|}
\hline No. & $\begin{array}{l}\text { Obstacles } \\
\text { Category }\end{array}$ & Main Obstacles & $\begin{array}{l}\text { Ways and Techniques } \\
\text { to Overcome }\end{array}$ \\
\hline & $\begin{array}{l}\text { Differences in } \\
\text { perceptions of } \\
\text { each party } \\
\text { regarding: }\end{array}$ & $\begin{array}{l}\text { - Lack of relevant in- } \\
\text { formation } \\
\text { - The merits of each } \\
\text { party's respective } \\
\text { position } \\
\text { - The risks }\end{array}$ & $\begin{array}{l}\text { - Get basic information re- } \\
\text { garding your partner be- } \\
\text { fore starting negotiations } \\
\text { - Exchange information and } \\
\text { seek help in interpreting it } \\
\text { - Ask for help in interpreting } \\
\text { the information } \\
\text { - See the strengths of each } \\
\text { other's arguments } \\
\text { - See the weaknesses of each } \\
\text { other's arguments } \\
\text { - Anticipate the conse- } \\
\text { quences of not reaching an } \\
\text { agreement }\end{array}$ \\
\hline 2. & $\begin{array}{c}\text { Cognitive } \\
\text { aspects }\end{array}$ & $\begin{array}{l}\text { - Lack of relevant } \\
\text { knowledge } \\
\text { - Selective interpre- } \\
\text { tation } \\
\text { - Overconfidence } \\
\text { - Unrealistic expecta- } \\
\text { tions } \\
\text { - Lack of interest in } \\
\text { the perspective or } \\
\text { interest of the other } \\
\text { party } \\
\text { - Lack of confidence } \\
\text { - Loss aversion } \\
\text { Distrust the other } \\
\text { party's offers }\end{array}$ & $\begin{array}{l}\text { - Utilize rigorous criteria to } \\
\text { analyse arguments/posi- } \\
\text { tions } \\
\text { - Focus on the weaknesses } \\
\text { of your own arguments/ } \\
\text { positions and the strengths } \\
\text { of the other's } \\
\text { - Emphasize the benefits of } \\
\text { reaching an agreement } \\
\text { - Pursue mutually beneficial } \\
\text { objectives } \\
\text { - Frame offers and conces- } \\
\text { sions in positive, optimistic } \\
\text { terms } \\
\text { - Be transparent }\end{array}$ \\
\hline 3. & $\begin{array}{l}\text { Emotions and } \\
\text { feelings }\end{array}$ & $\begin{array}{l}\text { - Different personal- } \\
\text { ities involved } \\
\text { - Feeling the need to } \\
\text { vindicate yourself } \\
\text { - Negative emotions } \\
\text { (anger, frustration, } \\
\text { envy, guilt, embar- } \\
\text { rassment) }\end{array}$ & $\begin{array}{l}\text { - Open with informal dis- } \\
\text { cussion } \\
\text { - Encourage parties to } \\
\text { openly express their } \\
\text { feelings } \\
\text { - Take the other party's } \\
\text { feelings into account } \\
\text { - Try to soften the impact of } \\
\text { both parties' emotional } \\
\text { concerns } \\
\text { - Be constructive }\end{array}$ \\
\hline 4. & $\begin{array}{l}\text { Strategic } \\
\text { barriers }\end{array}$ & $\begin{array}{l}\text { - Differences between } \\
\text { personal and organi- } \\
\text { zational strategies } \\
\text { and tactics } \\
\text { - Unwillingness to ne- } \\
\text { gotiate }\end{array}$ & $\begin{array}{l}\text { - Inform on the organization } \\
\text { strategies and tactics } \\
\text { - Keep the negotiations } \\
\text { period short and sweet } \\
\text { - Demand commitment to } \\
\text { the process }\end{array}$ \\
\hline
\end{tabular}


Table 6.2 (Continued)

\begin{tabular}{|c|c|c|c|}
\hline No. & $\begin{array}{l}\text { Obstacles } \\
\text { Category }\end{array}$ & Main Obstacles & $\begin{array}{l}\text { Ways and Techniques } \\
\text { to Overcome }\end{array}$ \\
\hline & & $\begin{array}{l}\text { - Entrenched posi- } \\
\text { tions } \\
\text { - Unaligned interests }\end{array}$ & $\begin{array}{l}\text { - Ensure the presence of } \\
\text { people with decision- } \\
\text { making capacity } \\
\text { - Make and demand offers } \\
\text { - Identify the other party's } \\
\text { intentions and try to } \\
\text { clarify ambiguous moves } \\
\text { - Warn the other party } \\
\text { about the impact of their } \\
\text { chosen action on the ne- } \\
\text { gotiation } \\
\text { - Reformulate the other } \\
\text { party's positions } \\
\text { - Generate ideas and crea- } \\
\text { tive solutions to conflict } \\
\text { - Avoid confrontation } \\
\text { - Use a win-win approach }\end{array}$ \\
\hline
\end{tabular}

Adapted from five ways managers can enhance their mediating skills, by K. Mehta \& I. Ripol, 2017, (p. 55), IESE Insight Business Knowledge

work is relationship. Things, events and places are not first selfcontained entities - already and always related one to another". As a result, the best way to see an individual is in context, and strong relationality can be used to reframe the negotiation.

A relational approach to negotiation generates many advantages, such as: it enhances perspective-taking ability, increases cooperation, reduces a sinister approach, stimulates creative processes, takes more care of the counterpart's emotions, increases the desire to work together in the future, etc. (Cheng, Huang, \& Su, 2017; Ingerson, DeTienne, \& Liljenquist, 2015; Slife \& Wiggins, 2009).

All elements presented are arguments in order to change in practice, in companies' stakeholder managerial synapse, from the paradigm promoted by instrumentalism - "competitive approach" - to the new paradigm, "cooperative or distributive approach", which is able to satisfy the needs and interests of both relevant stakeholders. The success of using the cooperative paradigm depends heavily on company managers' ability to adopt a relational approach in the negotiation and - to a large degree - on the other relevant stakeholder adoption of the negotiation paradigm.

In the case of a relevant outside company stakeholder, before the negotiation process, it could be useful to use the recently introduced new approach known as "shaking stakeholders" (Sulkowski, Edwards, \& Freeman, 2018). This means proactively initiating cooperation with 
stakeholders affected by the company, to alter awareness behaviour and networks so as to catalyse change in society and the marketplace, to reward co-creating innovation in the core operation of the company that improves social and environmental impacts. Shaking stakeholders is helpful in initiating and developing win-win negotiation and performant collaboration with relevant stakeholders and in constructing a successful managerial synapse.

Win-win negotiation, based on the multifaceted motivation of the relevant stakeholders involved, has a determinant impact on the managerial synapse construction, work and performance.

\section{Strong Motivation Content and Engagement of the Managerial Synapse Components}

A managerial synapse is one of the most motivational managerial mechanisms that can be used in a company today. The main arguments are as follows:

- managerial synapse objectives, common to both components, are determined by win-win negotiations. This means that the manager and the relevant stakeholder are very strongly motivated to decide, act and behave - each and together - to accomplish the synapse objectives at a very high level;

- targets to be fulfilled by manager and relevant stakeholder are formulated together, taking into consideration common objectives, also using win-win negotiations. Therefore, each synapse component accomplishes the undertaken and desirable work processes, which correspond to individual preferences, expectations and capabilities;

- setting by direct win-win negotiation of the common objectives and tasks, provides the necessary premise, that starting from the beginning of the managerial synapse, to decide the evaluation criteria for the manager and the stakeholder performances. This approach higher motivate them. Such an approach has a positive impact both on the work processes content and on the intense motivation for effort, creativity, and performance;

- in the designing of the managerial synapse, the synapse area is determined, characterized by intense dialogic communication, reciprocity, collaboration, and cooperation, elements that contribute greatly to further motivating the managerial synapse components and, simultaneously, providing better conditions for intense efforts and creativity, favouring the increase of individual and organizational performance;

- in the managerial synapse construction and work, we can use new approaches - like meaningful work, positive identity or agile work capable of facilitating the design and accomplishment of certain 
work processes congruent with the manager and relevant stakeholder's personality and characteristics. This facilitates and enhances the flexible and innovative work processes progress, which is able to generate not only better results, but also a positive attitude and multiple satisfactions, determined by the strong implication of the managerial synapse constituencies;

- a managerial synapse, through all of its characteristics, represents a stimulative work environment for greater efforts and creativity, an environment enabling the better use and valorification of the managerial synapse components' qualities, in order to fulfil the common objectives negotiated.

The above-presented elements, while not exhaustive, demonstrate the high motivational content of the managerial synapse. In this context, we specify that it is recommended to use a comprehensive set of motivations - general and specific - aimed at increasing the manager and relevant stakeholder's intense employment of their qualities, growth potential, work efforts and the contextual conditions. In Table 6.3, we propose a set of such comprehensive elements using the orientative goals-motivation matrix. The matrix incorporates two categories of elements grouped in two lists:

- a list with the most frequent goals to be achieved in the organizations by the employees. These goals are the background for the determination of the joint concrete objectives for managerial synapse components;

- a list with a set of approaches and tools used in performant companies in order to motivate the employees. This list facilitates the construction of a very powerful incentives system for the managerial synapse components, taking into consideration the fact that stakeholders are multifaceted, dealing with intrinsic and extrinsic motivations. We have selected the motivational tools and approaches from the best practices used in European and North American companies.

The matrix represents a general framework that should be adapted to the conditions of each company - organizational culture or subcultures, general strategy and policies, the human resources management practised in the organization, etc. In the matrix, only the motivational approaches and tools that are in line with the company's motivational approach should remain. A list with the motivational approaches should be analysed and defined by the human resources department, with the approval of the company's top management. This is a very good opportunity for the company to diversify and to enrich the motivational approaches and tools used in the organization. For the company's competitivity and sustainability, it is essential that the organization rewards long-term performance and tolerates early failures (Harrison \& Wicks, 2013). 


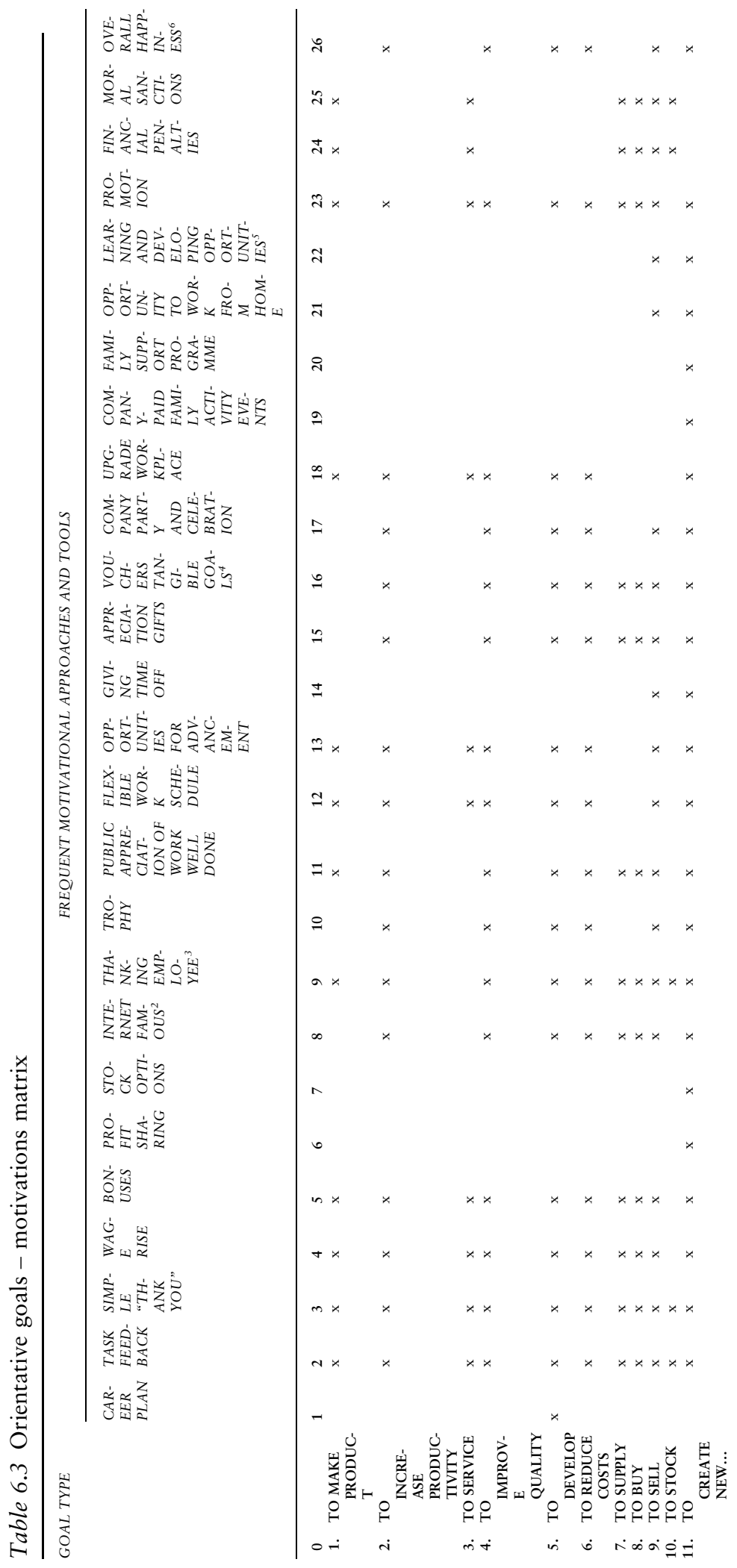




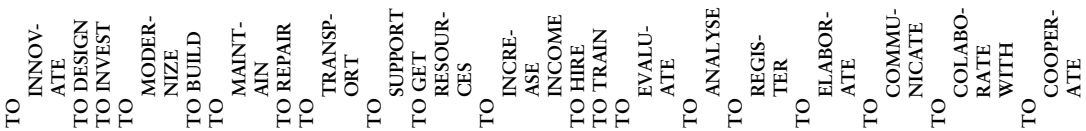

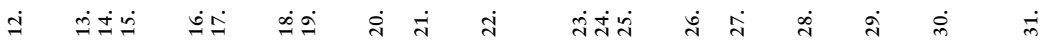




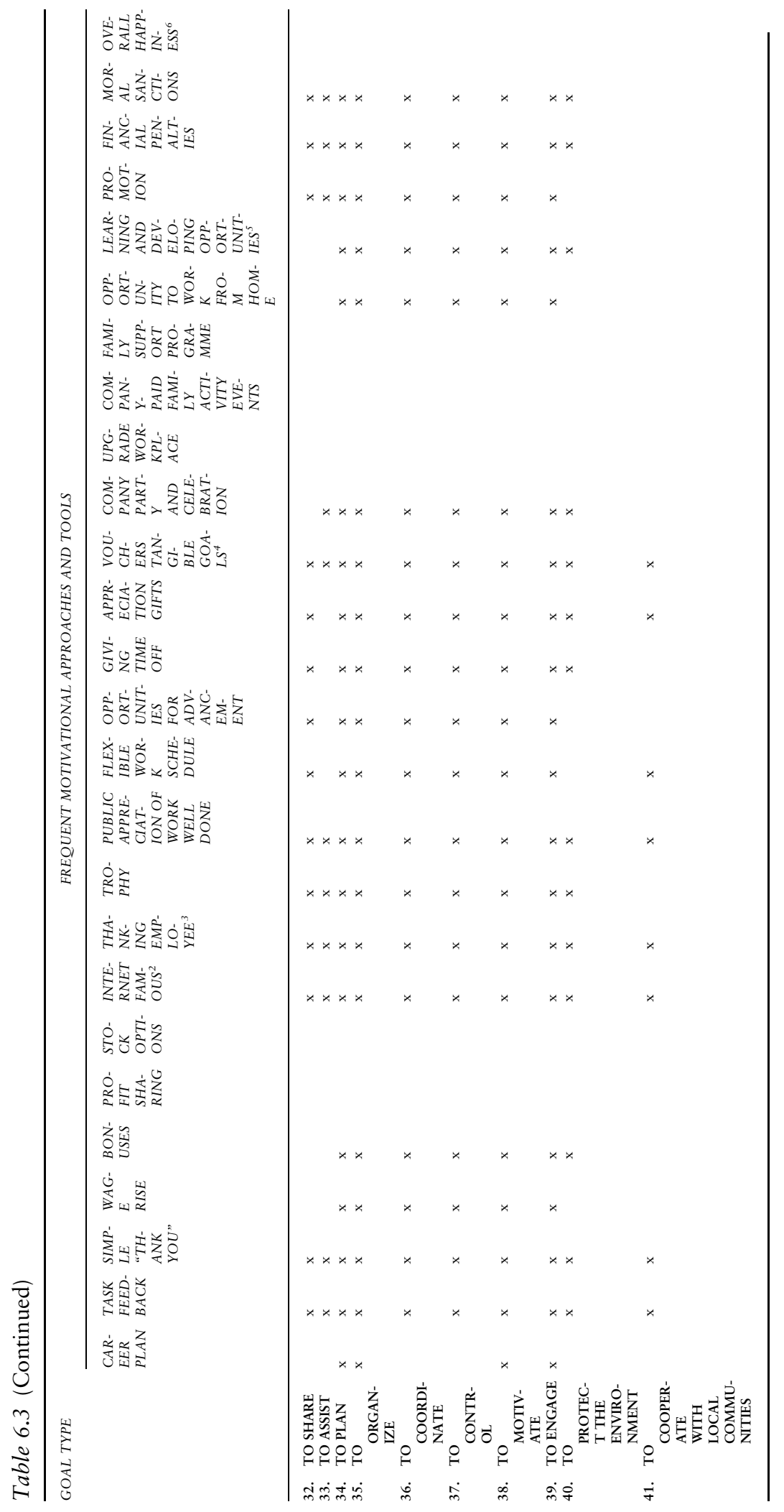


Company lists of goals and motivational approaches should be used in a participative approach by the components of each managerial synapse. It is useful to employ the list from the beginning in the design of the synapse. The list of goals can help the manager and the stakeholder to select rationally the suitable joint objectives of the synapse. In accordance with the goals taken into consideration and the joint objectives negotiated based on a win-win approach, the synapse components are able to determine - using the matrix - the best motivational approaches and tools for them and for the organizations involved.

Motivational approaches should be differentiated and personalized for each managerial synapse and for each manager and stakeholder, taking into consideration mainly the following elements:

- synapse joint objectives;

- the nature and complexity of the tasks to be accomplished by each component;

- individual characteristics of the manager;

- motivational specificity of the manager;

- individual characteristics of the relevant stakeholder;

- motivational specificity of the relevant stakeholder;

- other special requirements regarding the workplace and organization involved, like those generated by the COVID-19 pandemic.

Such an approach could help in constructing a positive workplace for each component of the synapse that is able to provide a stimulating work environment.

Motivation is dynamic, it changes over time. For this reason, periodically, the motivational approaches and tools used should be analysed and modified, taking into consideration the new elements inside and outside the managerial synapse and in the company and other organizations, in order to enhance the performance of both the components and the company. In the case of exponential changes in the company environment, like those caused by the Covid pandemic, the motivational tools should also be reconsidered.

Recently, a formal model has been developed linking the design of firms' incentive structures to their rate growth. The associated dynamics lead to three distinct approaches of firms' life cycle and of the employees' motivation:

- rapid growth and high-powered incentive driven by frequent promotion opportunities;

- moderate growth with infrequent promotion opportunities, but large salary increases contingent on promotion;

- finally, stagnant firms with low-powered incentives (Bennett \& Levinthal, 2017). 
Such a model could be very useful for the development of the motivation system in each company, based on an in-depth analysis of its activities and performance, helping to improve the motivation of the relevant stakeholders.

All elements regarding managerial synapse motivation demonstrate that this new managerial mechanism is able to contribute to a large extent to the individual stakeholders' engagement, which is very beneficial for the company. A research conducted in the last few years has proved that organizations with engaged employees have three times higher profit margins than those with disengaged employees (Sacks, 2017).

\section{Major Role Played by Stakeholder Perceptions in Managerial Synapse Construction and Work}

As we know, individual perception regarding what is happening around one is always very important. Perception, by definition, is subjective; it reflects how a person obtains, understands, interprets, presents, communicates and uses information regarding an event, activity, other individuals, etc. There are often differences between reality and a person's perceptions of it. The same reality could be perceived more or less exactly the same way depending on the context and, in particular, on the characteristics and the behaviours of the people involved. The emotional intelligence of each person and the specific emotions felt by him or her at the moment of perception have a major influence on the content and significance of that perception. This explains to a large extent why the same reality generates different perceptions in various individuals. Of course, different perceptions are reflected in different information disseminated, decisions taken, actions performed and behaviour adopted.

Perceptions are very important in general, in all activities. The dimension of the importance of perception can be different depending on the nature of the processes involved. In the case of technical, mathematical, informational and other similar processes, which can be very precisely measured using rigorous instruments and methods, the individual perceptions of reality are usually identical or at least similar. In business, social, managerial or administrative activities, where qualitative elements are predominant, they frequently cannot be measured exactly and the perceptions of them can vary to a significant extent from one person to another. A study carried out by a group of very wellknown specialists - Peloza, Loock, Cerruti, \& Muyot (2012) - based on empirical research in three companies demonstrated that "there is often a major gap between stakeholders' perceptions and firm performance". In all these types of activities - which represent the majority in society and the economy - the perceptions quite often have more of an influence than the reality, the thinking, decisions, actions, and behaviours of the people and groups of people involved. 
In the case of a managerial synapse perceptions are even more important than in the daily business and managerial activities of the organization. Three main arguments support this statement:

a The relevant stakeholder of a company's managerial synapse is more sensitive to the decisions, actions and behaviours of the manager who represents the company in the synapse, because usually he/she has more competences and powers concerning the allocation of the organization's resources in achieving the joint goals and expectations and in initiating changes in their bilateral relationships.

b Each relevant stakeholder, each component of the synapse, decides, acts, and behaves based to a large extent on the perceptions regarding the decisions, actions and behaviours of the other component of the managerial synapse. If the perceptions are positive, it is quite probable that his/her feedback inside the managerial synapse will be constructive, contributing to its good work and to the achievement of the joint goals, objectives and expectations. Recent researches have stated that the perception of fairness mediates to a large extent the relationships between stakeholders through positive and negative mutual behaviours (Bosse \& Phillips, 2016).

c The perceptions of all internal and external company stakeholders regarding what has happened in each managerial synapse associated with the organization influence their desire and decision to be component, to continue and/or to develop relationships with the company, included the component of a future managerial synapse. The reputation and prestige of each company, which to an important extent reflect the perceptions of the organization's stakeholders local community, mass media, administrative authority, and public opinion - are essential elements impacting the company's capacity to construct performant managerial synapses. Perceptions are determinant not only of the organization's reputation and prestige, but also of the existence and size of its "trust capital".

The influence of perception on a company's performance is so large that it has led to certain specialists declaring (asserting) that perceptions optimize the total value created in a company more than financial performance (Harrison \& Wicks, 2013). The information presented indicates why a company that wants to develop performant managerial synapses valorizing the huge potential of the internal and external stakeholders should pay special attention to the relevant stakeholders' perceptions. The characteristics of company culture, the quality of organizational leadership, the organizational shareholders' and managers' personalities and behaviours play a major role in achieving a realistic and positive perception regarding what happens in the company, as an entity, and at the level of its components. A special programme aimed at making 


\section{8}

company stakeholders aware of the importance of their perceptions and developing them positively in order to contribute better work and development to the company - including by using managerial synapses - is recommended and could be extremely useful. Such a programme is even more necessary when in the company context there are crises like that created by the COVID-19 pandemic and when people are surrounded by negativity everywhere they turn (Porath \& Porath, 2020).

\section{Two Alternative Approaches to Constructing and Implementing a Managerial Synapse}

The new managerial mechanism - the managerial synapse - could be used in companies in two different ways. The first is to implement the managerial synapse as such, like an autonomous mechanism, within the framework of the current managerial system of the company. This means having separate managerial synapses for some of the company's relevant stakeholders. This is a similar situation to what happens now in companies that utilize CRM and SCM. The second approach is to redesign the whole company management by building managerial synapses for all relevant stakeholders and correlating and integrating them to create a global management system within the organization - a company-relevant stakeholder-based management system.

The main arguments for the selective use of a managerial synapse for certain relevant stakeholders are presented in Table 6.4.

There are also many arguments favouring the use of managerial synapses as integrated components of the relevant company stakeholderbased management system. ${ }^{7}$ In Table 6.5 , we formulate these arguments.

Remodelling an organization's management by implementing a relevant stakeholder-based management system is not an easy task. There are a number of difficulties to be overcome: the complexity of the processes involved, the need to learn and apply a new methodology in order to construct a stakeholder-based management system within the organization, the time-consuming nature of the task, the notable costs involved, the relevant stakeholders, their diversity and often the large number of them, among others.

Taking into consideration the advantages and difficulties mentioned, we recommend an approach to implementing a company-relevant stakeholder-based management system structured in two parts:

a First, the construction of managerial synapses for the most important relevant stakeholders, when there are good premises to be successful and to rapidly achieve high performances for both synapse components. By doing this, the company can benefit from all the advantages presented in Table 6.5. The know-how and the benefits generated by building and operating these managerial synapses will 
Table 6.4 Main advantages of using separate managerial synapses

\begin{tabular}{l} 
No. $\quad$ Advantages \\
\hline 1. It is much easier, faster and less costly to build and use separate \\
managerial synapses than to design, build and implement a \\
stakeholder-based management system throughout the company. \\
It offers the possibility of remodelling the company's relations with the \\
relevant stakeholders rapidly and benefiting sooner from this \\
managerial innovation.
\end{tabular}

represent a very good preparation from all points of view managerial, psychological, economic, social, ecologic, etc. - for the company management and its relevant stakeholders, leading to the next step of building a stakeholders' company management system.

b Second, continuing with the construction of a company-relevant stakeholder-based management system that will cover the entire organization and all its relevant stakeholders. The complexity of this system is much bigger than a managerial synapse and building it is more complicated and costly as we shall demonstrate in the next chapter. But the experience and know-how gained in the previous step with the managerial synapse will be very useful, contributing to accelerating the building and implementation of the companyrelevant stakeholder-based management system and to increasing the business, social and ecological benefits for the organization and the relevant stakeholders.

The top management of each company should decide how to approach and implement the management of the relevant stakeholders, taking into consideration the specific conditions of the organization and the 
Table 6.5 Main arguments for implementing a company-relevant stakeholderbased management system

\begin{tabular}{|c|c|}
\hline & Arguments \\
\hline 1. & $\begin{array}{l}\text { A company-relevant stakeholder-based management system provides the } \\
\text { opportunity to take full advantage of the new approach for all } \\
\text { relevant internal and external company stakeholders, without losing } \\
\text { none of them. }\end{array}$ \\
\hline 2. & $\begin{array}{l}\text { A company-relevant stakeholder-based management system facilitates } \\
\text { more business, social and ecological performances for the company, } \\
\text { because of the contribution of all relevant stakeholders. }\end{array}$ \\
\hline 3. & $\begin{array}{l}\text { A company-relevant stakeholder-based management system creates a } \\
\text { managerial mechanism capable of correlating and integrating } \\
\text { effectively all organization managerial synapses, according to the } \\
\text { company strategy. }\end{array}$ \\
\hline 4. & $\begin{array}{l}\text { The work and performance of each managerial synapse are maximized } \\
\text { when they are part of the company's stakeholder-based management } \\
\text { system. }\end{array}$ \\
\hline 5. & $\begin{array}{l}\text { A company-relevant stakeholder-based management system generates } \\
\text { business synergy and sustainability in the company by harmonizing } \\
\text { the objectives, decisions, actions and behaviours of the relevant } \\
\text { stakeholders, both at the level of each managerial synapse and at the } \\
\text { level of the whole organization. }\end{array}$ \\
\hline 6. & $\begin{array}{l}\text { A company-relevant stakeholder-based management system increases } \\
\text { the capacity of the organization to face VUCA elements, contributing } \\
\text { to taking better advantage of the multiple trends and opportunities } \\
\text { and to reducing the effects of threats, which are becoming increasingly } \\
\text { frequent under the impact of the present digital revolution. }\end{array}$ \\
\hline
\end{tabular}

characteristics of the relevant stakeholders. Analysis of the variables that influence the construction and work of the managerial synapse is strongly recommended (see Figure 6.1).

After deciding what approach is to be used, the company management needs to elaborate, together with the relevant stakeholders involved, a detailed implementation programme.

\section{Guide for Managerial Synapse Construction, Work, and Development}

This guide contains the main phases to be completed in order to construct and operate performant managerial synapses in a company (see Figure 6.3). The guide is comprised of 14 phases. The first five phases are focused on the construction of the synapse, the following six phases on its functioning and the last three steps on the generation of performance for both synapse components and, of course, for the entire company.

In the company, as a rule, all phases incorporated in the guide are necessary in the development of a managerial synapse. The content and 


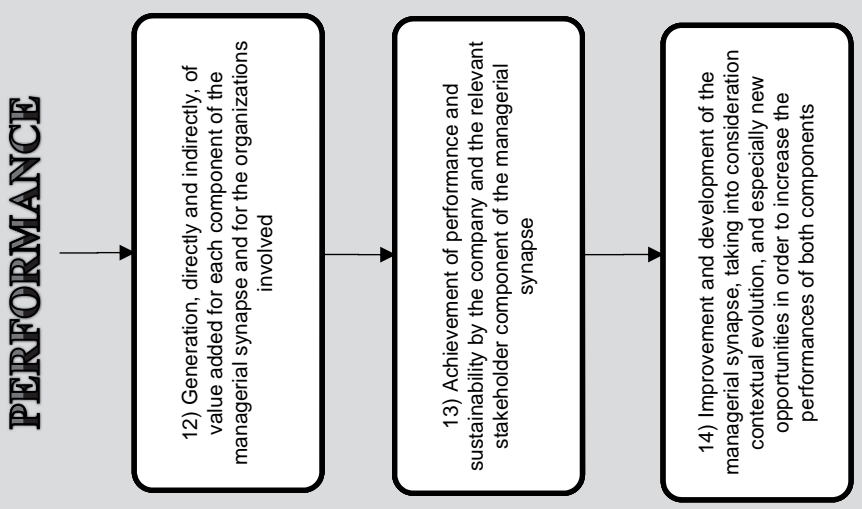

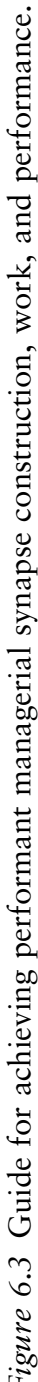
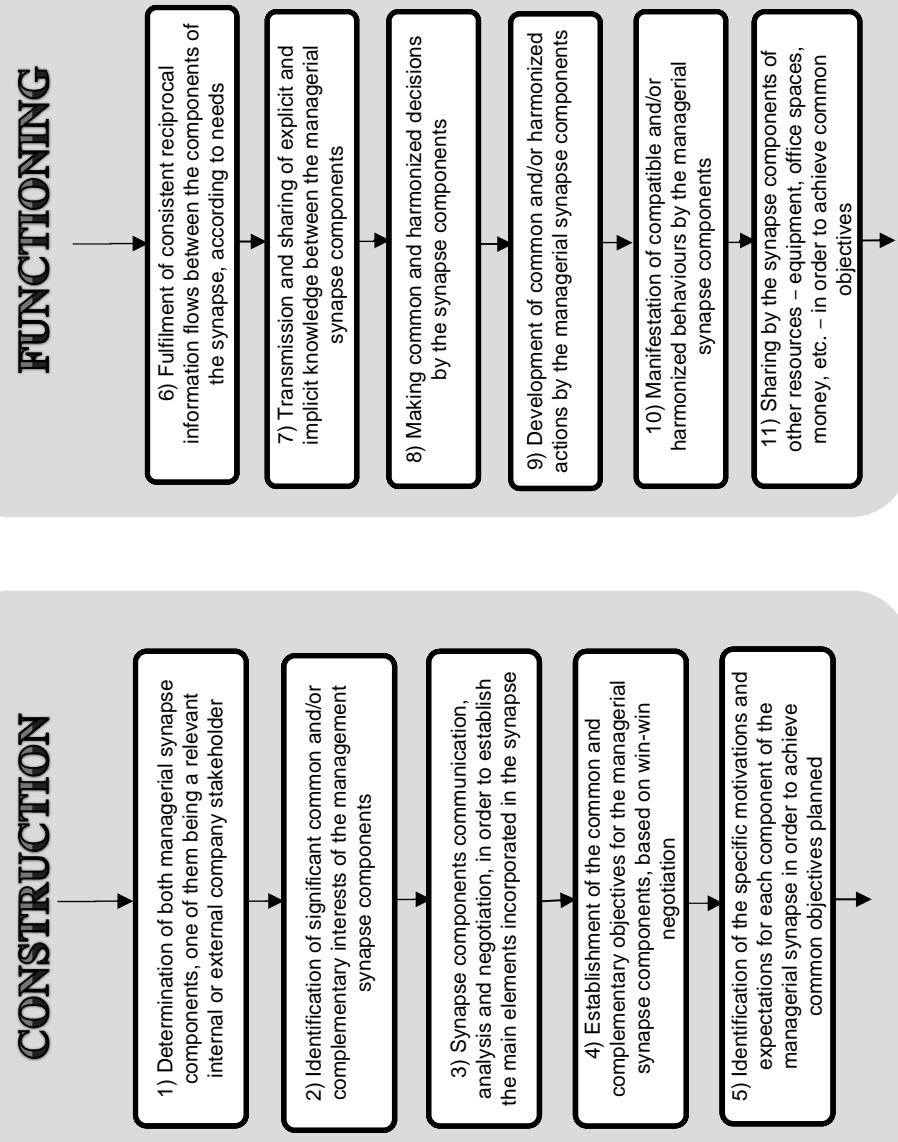


\section{Building of the Managerial Synapse}

importance of each phase could differ partially from one type of managerial synapse to another. It is essential to take into consideration the logic of the entire guide in a creative and rigorous manner, in the case of each managerial synapse.

In the context of the COVID-19 pandemic crisis, this guide could help to construct or reconstruct functional and performant relationships with some important stakeholders, thereby accelerating the company's recovery and its sustainable development.

\section{Notes}

1 Managerial synapses have been grouped taking into consideration, mainly, the frequency of the managerial relationships involved.

2 Internet famous contains: appreciations of employee on the company website, email with employee appreciation to everyone in the company, employee work business impact report on the company website, announcement with star of the month, etc.

3 Thanking employee forms: praising employee, certificate of achievement, announcing an accomplishment at a company meeting, personal note of praise from manager, letter with thanks, handwritten appreciation note, etc.

4 Vouchers tangible goals for: free or subsidized meals, fruits or drinks, sporting events, artistic events, paid group meals, wellness programme, and other holiday vouchers.

5 Learning and development opportunities like: conference participation, training programmes, exhibition visit, mentoring, coaching, tutoring, counselling, etc.

6 Overall happiness, see the analysis of Harrison and Wicks (2013).

7 Company-relevant stakeholders-based management system shall be presented in Chapters 9 and 10 of the book.

\section{References}

Bennett, V. M., \& Levinthal, D. A. (2017). Firm lifecycles: Linking employee Incentives and firm growth dynamics. Strategic Management Journal, 38(10), 2005-2018. doi:10.1002/smj.2644

Bosse, D. A., \& Phillips, R. A. (2016). Agency theory and bounded self-interest. Academy of Management Review, 41(2), 276-297. doi:10.5465/amr.2013. 0420

Bridoux, F., Coeurderoy, R., \& Durand, R. (2017). Heterogeneous social motives and interactions: The three predictable paths of capability development. Strategic Management Journal, 38(9), 1755-1773. doi:10.1002/smj.2605

Brown, J. A., Gianiodis, P., \& Santoro, M. D. (2017). Managing co-opetition for shared stakeholder utility in dynamic environments. California Management Review, 59(4), 114-139. doi:10.1177/0008125617705868

Cheng, J., Huang, Y., \& Su, Y. (2017). Relationality in negotiations: Systematic review and propositions for future research. International Journal of Conflict Management, 28(3), 295-321. doi:10.1108/IJCMA-12-2015-0091

Creech, B. (1994). The five pillars of TQM: How to make total quality management work for you. New York: Truman Talley Books/Plume. 
Drucker, P. F. (1954). The practice of management. New York: Harper Business. Hahn, T. (2015). Reciprocal stakeholder behavior: A motive-based approach to the implementation of normative stakeholder demands. Business \& Society, 54(1), 9-51. doi:10.1177/0007650312439029

Harrison, J. S., \& Wicks, A. C. (2013). Stakeholder theory, value and firm performance. Business Ethics Quarterly, 23(1), 97-124. doi:10.5840/beq2 0132314

Ingerson, M. C., DeTienne, K. B., \& Liljenquist, K. A. (2015) Beyond instrumentalism: A relational approach to negotiation. Negotiation Journal, 31(1), 31-46. doi: 10.1111/nejo.12078

Johns, G. (2017). Reflections on the 2016 decade award: Incorporating context in organizational research. The Academy of Management Review, 42(4), 577-595. doi:10.5465/amr.2017.0044

Juran, J. M. (1995). A history of managing for quality: The evolution, trends, and future directions of managing for quality. Milwaukee, WI: ASQC Quality Press.

Manning, T. (2017). The development and use of a contingency model of objective setting. Industrial and Commercial Training, 49(6), 288-295. doi:10.1108/ICT-07-2017-0055

Mehta, K., \& Ripol, I. (2017). 5 ways managers can enhance their mediating skills. IESE Insight Business Knowledge, 34, 53-60.

Odiorne, G. S. (1965). Management by objectives: A system of managerial leadership. New York: Pitman Publishing.

Olekalns, M., \& Druckman, D. (2014). With feeling: How emotions shape negotiation. Negotiation Journal, 30(4), 455-478. doi:10.1111/nejo.12071

Peloza J., Loock, M., Cerruti, J., \& Muyot, M. (2012). Sustainability: How stakeholder perceptions differ from corporate reality. California Management Review, 55(1), 74-97. doi:10.1525/cmr.2012.55.1.74

Porath, C., \& Porath, M. (2020). How to thrive when everything feels terrible. Harvard Business Review. Retrieved from https://hbr.org/2020/10/how-tothrive-when-everything-feels-terrible

Rey, C., Velasco, J. S. C., \& Almandoz, J. (2019). The new logic of purpose within the organization. In C. Rey, M. Bastons, \& P. Sotok (Eds.), Purposedriven organizations (pp. 3-15). Cham: Palgrave MacMillan. Retrieved from https://link.springer.com/content/pdf/10.1007\%2F978-3-030-17674-7_1.pdf. 10.1007/978-3-030-17674-7_1

Sacks, A. M. (2017). Translating employee engagement research into practice. Organizational Dynamics, 46(2), 76-86. doi:10.1016/j.orgdyn.2017.04.003

Slife, B. D., \& Wiggins, B. J. (2009). Taking relationship seriously in psychotherapy: Radical relationality. Journal of Contemporary Psychotherapy: On the Cutting Edge of Modern Developments in Psychotherapy, 39(1), 17-24. doi:10.1007/s10879-008-9100-6

Sulkowski, A. J., Edwards, M., \& Freeman, R. E. (2018). Shake your stakeholder: Firms leading engagement to cocreate sustainable value. Organization \& Environment, 31(3), 223-241. doi:10.1177/1086026617722129 